\title{
Nasal ketamine for paediatric premedication
}

Natan Weksler MD, Leon Ovadia MD, Gabi Muati MD, Anatoli Stav MD irritability, is higher after stormy induction of anaesthesia.

Children less than five years old are more vulnerable to those changes, because they are too young to understand the reasons for the unpleasant experience. ${ }^{2}$ Therefore, it is desirable that they reach the operating room asleep.

The ideal premedicant drug for children should be easy to administer, induce sedation rapidly, not prolong the recovery after short procedures, and make anaesthetic induction less traumatic. Ketamine has been advocated for paediatric premedication, given either $i m,{ }^{3}$ or $p r{ }^{4}$ However, most children object to injections, and many to the introduction of tubes in their anus which makes premedication administration traumatic.

Henderson et $a l .{ }^{4}$ reported good results with nasal administration of sufentanil as preinduction treatment for surgical paediatric patients, and recommended the nasal route for premedication in children. Since ketamine, in low doses, has most of the characteristics of the ideal premedicant drug, we evaluated its efficacy when administered nasally to the paediatric patient.

\section{Methods}

After the approval of the Hillel Yaffe Medical Center Ethical Committee, and obtaining parental consent, we studied 148 ASA I and II children aged from two to five years undergoing elective general, urological, or plastic surgery. Eighty-six children (mean age $3.5 \pm 1.3 \mathrm{yr}$ ), received $6 \mathrm{mg} \cdot \mathrm{kg}^{-1}$ of nasally administered ketamine, 20 to $40 \mathrm{~min}$ before the scheduled surgery time (Group 1). These children were compared with 62 others also aged from two to five years (mean age $3.2 \pm 1.4 \mathrm{yr}$ ) in whom promethazine and meperidine $1 \mathrm{mg} \cdot \mathrm{kg}^{-1}$ each were injected im (Group 2).

The study was undertaken double-blind and each child received, in a random fashion, either ketamine $1.2 \mathrm{ml} \cdot 10$ $\mathrm{kg}^{-1}$ (50 $\mathrm{mg} \cdot \mathrm{ml}^{-1}$ solution) administered nasally and 1 $\mathrm{ml} \cdot 10 \mathrm{~kg}^{-1}$ saline $0.9 \% \mathrm{im}$, or saline $0 / 9 \% 1.2 \mathrm{ml} \cdot \mathrm{kg}^{-1}$ administered nasally and $1 \mathrm{ml} \cdot 10 \mathrm{~kg}^{-1}$ of a solution containing $10 \mathrm{mg}$ of meperidine and $10 \mathrm{mg}$ of promethazine per $\mathrm{ml} \mathrm{im}$. The solutions were prepared and administered by an anaesthetist not involved in the study. Sedation was stated, by the room anaesthetist, as excellent if the 
TABLE Demographic variables

\begin{tabular}{lll}
\hline & Group l & Group 2 \\
\hline Age (yr) & $3.5 \pm 1.3$ & $3.2 \pm 1.4$ (NS) \\
Female/Male ratio & 0.55 & 0.5 (NS) \\
Weight $(\mathrm{kg})$ & $15.7 \pm 4.3$ & $14.9 \pm 3.2$ (NS) \\
Site of surgery $(n)$ & & \\
Urological & 28 & 18 \\
General & 42 & 36 \\
Plastic & 10 & 14 \\
\hline
\end{tabular}

child did not object to the face mask, adequate if there was slight resistance, or failed if the child strongly resisted and pushed the mask away. The patients were observed for salivation, which was graded as: 0 - none; 1 - mild; 2 - moderate; 3 - copious.

In the recovery room, the children were observed for emergence phenomena (visual, auditory, proprioceptive and confusional illusions) by the ward nurse, who was unaware which premedication had been administered to each patient.

The recovery time was defined as the interval from discontinuation of the anaesthetic gases until the patient reached the Aldrete Post-anaesthetic Recovery Score $\geq$ 6. ${ }^{6}$ Data are expressed as mean \pm SD. Fisher's exact test was used for statistical analysis and a level of $P<$ 0.05 was considered to be significant.

\section{Results}

Both groups were similar in age, weight, sex and site of surgery (Table).

Sedation was excellent in 48 , and adequate in 19 patients of the ketamine group, compared with nine and 12 respectively in Group $2(P<0.05)$ (Figure 1). Salivation was graded as 1 in 35 of Group 1 and in 28 of Group 2 patients, 2 in 39 and 26 respectively, and 3 among the remainder (NS) (Figure 2). The recovery time was $22.5 \pm 7.5 \mathrm{~min}$ in Group 1 and $20.8 \pm 6.5$ min in Group 2 (NS). Emergence reactions did not occur in any of the children.

\section{Discussion}

Unpremedicated children frequently object to inhalational induction, and they often feel that the use of needles is one of the most worrisome aspects of the hospital stay. ${ }^{7}$ Children aged two to six years are specially vulnerable to this problem, since their understanding is limited. ${ }^{8}$ Therefore, these children should be premedicated, in order to allow smooth induction, decrease anxiety, and to prevent postoperative psychological and behavioural changes.

Promethazine and meperidine $1 \mathrm{mg} \cdot \mathrm{kg}^{-1}$ each are

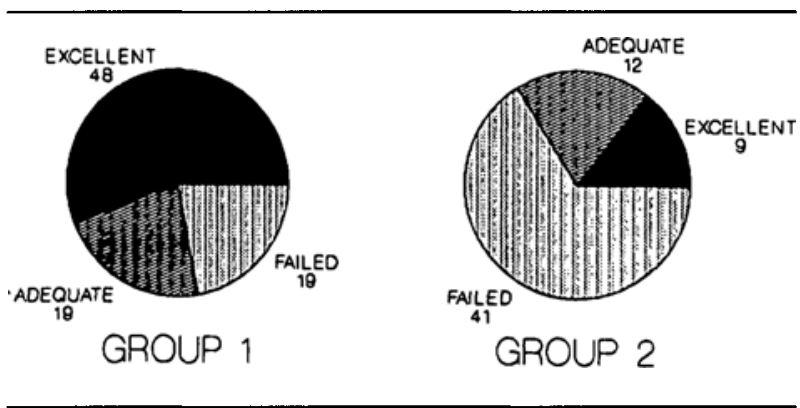

FIGURE I Quality of sedation $(P<0.05)$.

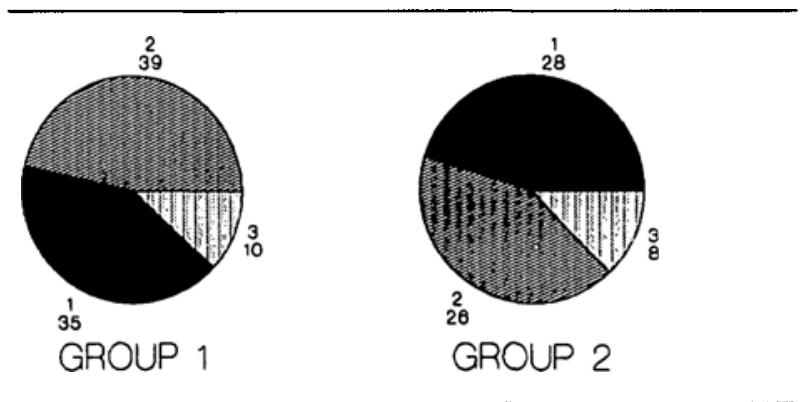

FIGURE 2 Grade of salivation $(P<0.05)$.

widely used for paediatric im premedication, but it was our impression that this regimen had an unacceptably high failure rate. Low dose im ketamine was indicated for preinduction sedation in the paediatric population. ${ }^{3}$ Nevertheless, the "fear of needles" is still present, which may make it undesirable for routine use in this setting.

Rectal administration of drugs is used for preinduction sedation in children, ${ }^{9,10}$ but many children would be reluctant to allow tube introduction in their anus, and insisting that a drug be administered in this way could be very traumatic for the paediatric patient. Since the use of nose drops is widely known, we speculated that this route could be well accepted by the children for premedicant drug instillation.

Nasal administration of sufentanil and midazolam has been recommended previously for premedication in children. ${ }^{5,11}$ However, both drugs may induce respiratory depression, ${ }^{12,13}$ which is a life-threatening complication and may limit their use.

Ketamine possesses many of the properties of the ideal premedication drug, such as rapid effect, low grade of respiratory depression, ${ }^{14}$ sedation and analgesia. ${ }^{4}$ However, emergence reactions, ${ }^{15}$ excessive salivation, ${ }^{16}$ and prolonged recovery time are frequently cited as reasons to limit its routine use. Nevertheless, its application for premedication has been recommended by either $i m,{ }^{3}$ or $p r^{17}$ routes. Despite the acceptable results, we believe that 
the children's fear is a limiting factor for the routine use of these routes.

A similar dose of oral ketamine $\left(6 \mathrm{mg} \cdot \mathrm{kg}^{-1}\right)$, was used successfully by Gutstein et al. for preanaesthetic medication in children, who recommended the use of the oral instead of the nasal route for paediatric premedication, since nasal premedications often leave a bitter taste and a burning sensation in the pharynx after administration. ${ }^{18}$ However, oral premedication, even when palatable and of small volume, is frequently rejected by small children. ${ }^{19}$ Further studies are necessary to determine the superiority of one route over the other.

Emergence reactions were not detected in any of our patients. Also, Hannallah and Patel ${ }^{3}$ as well as Gutstein and colleagues, ${ }^{18}$ did not detect emergence reactions among children receiving either low-dose im or po ketamine for preanaesthetic sedation. Hollister and Burn ${ }^{17}$ have demonstrated that the incidence of emergence reactions in children is lower than in adult patients, varying from 0 to $5 \%$ in the former, to $>30 \%$ in the latter.

We are aware of some ethical considerations in performing this study, since the children received either an im injection or a nasal instillation of saline, in order to assess in a double-blind fashion each form of premedication. However, the parents were informed and accepted the protocol. In addition, there was no saline-only control group, since in that case, no premedication would have been administered and no sedation obtained. Moreover, apart from the initial explanation, no particular effort was made to encourage the parents' agreement: simple reluctance automatically excluded the children. Surprisingly, no parent insisted on exclusion.

Our original intention was to perform a double-blind, randomized study, in two groups of 100 patients each. However, colleagues in our department were concerned about the ethical aspects of submitting the children to unnecessary injections. Therefore, we decided to interrupt the study, at this point, despite its approval by the local ethical committee and its acceptance by the parents.

In conclusion, nasal ketamine $6 \mathrm{mg} \cdot \mathrm{kg}^{-1}$ provides an effective paediatric premedication, and compares favourable with im promethazine and meperidine $1 \mathrm{mg} \cdot \mathrm{kg}^{-1}$ each, with regard to sedation and mask acceptance. Recovery time is not prolonged and excessive airway secretion was not seen. Nasal ketamine is useful for paediatric premedication, and offers an alternative to im or $p r$ routes for preanaesthetic sedation in young children aged from two to five years.

\section{References}

1 Eckenhoff JE. Relationship of anesthesia to postoperativepersonality change in children. Amer J Dis Child 1953; 86: $587-91$.
2 Anderson SM. Premedication of children for surgery. $\mathrm{Br} \mathrm{J}$ Anaesth 1960; 32: 125-31.

3 Hannallah RS, Patel RI. Low-dose intramuscular ketamine for anesthesia pre-induction in young children undergoing brief outpatient procedures. Anesthesiology 1989; 70: 598-600.

4 White PF, Way WL, Trevor AJ. Ketamine - its pharmacology and therapeutic uses. Anesthesiology 1982; 56: 119-36.

5 Henderson JM, Brodsky DA, Fisher DM, Brett CM, Hertzka RE. Pre-induction of anesthesia in pediatric patients with nasally administered sufentanyl. Anesthesiology 1988; 68: 671-5.

6 Aldrete $J A$, Kroulik $D$. A postanesthetic recovery score. Anesth Analg 1970; 49: 924-33.

7 Johnston CC. Preparing children for surgery. Canadian Operating Room Nursing Journal 1983; 1: 4-9.

8 Boezaart $A P$, van Hasselt $C H$. Induction of anaesthesia in children. S Afr Med J 1987; 71: 643-4.

9 Chayen MS, Sarnat $H$. Rectal premedication for small children. Anesth Analg 1973; 52: 837-8.

10 Goresky GV, Steward DJ. Rectal methohexitone for induction of anaesthesia in children. Can Anaesth Soc J 1979; 26: 213-5.

11 Walbergh EJ, Wills RJ, Eckhert J. Plasma concentration of midazolam in children following intranasal administration. Anesthesiology 1991; 74: 233-5.

12 Karl HW, Keifer AT, Rosenberger $J$, Larach MG, Ruffle $J M$. Comparison of the safety and efficacy of intranasal midazolam or sufentanil for preinduction of anesthesia in pediatric patient. Anesthesiology 1992; 76: 209-15.

13 Alexander CM, Gross JB. Sedative doses of midazolam depress hypoxic ventilatory responses in humans. Anesth Analg 1988; 67: 377-82.

14 Soliman $M G$, Brinale GF, Kuster $G$. Response to hypercapnia under ketamine anaesthesia. Can Anaesth Soc J 1975; 22: 486-94.

15 Fine J, Finestone SC. Sensory disturbances following ketamine anesthesia: recurrent hallucinations. Anesth Analg 1973; 52: 428-30.

16 Davenport HT. Paediatric Anaesthesia, 3rd ed., London: William Heinemann Medical Books Ltd, 1980.

17 Saint-Maurice C, Laguenie G, Couturier C, Goutail-Flaud $F$. Rectal ketamine in paediatric anaesthesia (letter). $\mathrm{Br} \mathrm{J}$ Anaesth 1979; 51: 573-4.

18 Gutstein HB, Johnson $K L$, Heard MB, Gregory GA. Oral ketamine preanesthetic medication in children. Anesthesiology 1992; 76: 28-33.

19 Madej TH, Paasuke RT. Anaesthetic premedication: aims, assessment and methods. Can J Anaesth 1987; 34: 259-73.

20 Hollister $G R$, Burn JMB. Side effects of ketamine in pediatric anesthesia. Anesth Analg 1974; 53: 264-7. 